\title{
Optimal Design of Leading Kinematical Chain of Eight Linked Planar Load Lifting Linkage
}

\section{Serikbay Kosbolov}

Doctor of Technical Sciences of Institute of Industrial Engineering after A. Burkitbayeva of Kazakh National Technical University kosbolov@mail.ru

\section{Ayaulym Rakhmatulina*}

Institute of Industrial Engineering after A. Burkitbayeva of Kazakh National Technical University Email:kazrah@mail.ru

\section{Nurbibi Imanbaeva}

Institute of Industrial Engineering after A. Burkitbayeva of Kazakh National Technical University

\author{
Algazy Zhauyt \\ Institute of Industrial Engineering after A. Burkitbayeva of Kazakh National Technical University \\ ali84jauit@mail.ru
}

\section{Doi:10.5901/mjss.2014.v5n23p2656}

\section{Abstract}

The problem of optimization of force transmission in planar linkage is concerned. New kinematical design of hoisting device with straight-line and translational motion of a platform is proposed. The method of optimal synthesis of leading kinematical chain of hydrocylinder is explored and multiobjective design is carried out based on Sobol-Statnikov's technique. Since the general solution of the modern theory problem of dynamics and strength of machines is absent, then it is an actual problem.

Keywords: Lifter, linkage, chain, link, design

\section{Introduction}

At many technological processes, especially at construction-installation, repairing works the mechanized load lifting mechanisms are highly required. However, at present time industrial and construction often uses "MOSI"-type and "building fences" type wood or metal equipments. These equipments are not reliable also it takes plenty of time to install them, materials are lifted to needed altitude by "hands".

As marketing analysis shows, there isn't any manufacturer of load lifting mechanisms in our country. "Nurnberg scissors" type load lifting mechanisms are produced abroad. But such load lifting platforms are very dangerous and might overturn since equipments' stiffness is low. Also these load lifting platforms are very heavy. The main reason is that the mechanism when in the built-up condition is close to singularity, that is why it is very big on reactions of kinematical chains, the value of balancing force is very high. For instance in some equipments it can be observed that balancing force is 16 times higher than lifted load.

\section{Statement}

So, it is necessary to work on how to make hydrocylindric chain useful in such load lifting mechanisms'. The actual problem is to produce high load lifting ability, low balancing force and light weighting mechanism types. Obtaining the equations of kinematics and force analysis and to write a programme in MS Excel Visual Basic. 


\section{Results}

The kinematical scheme of eight-linked planar load lifting joint linkage is shown in picture 1 which consists of movable links and 9 links. Degree of freedom $W=1$. Load lifting mechanism is made on the basis of four linked planar joint linkage.

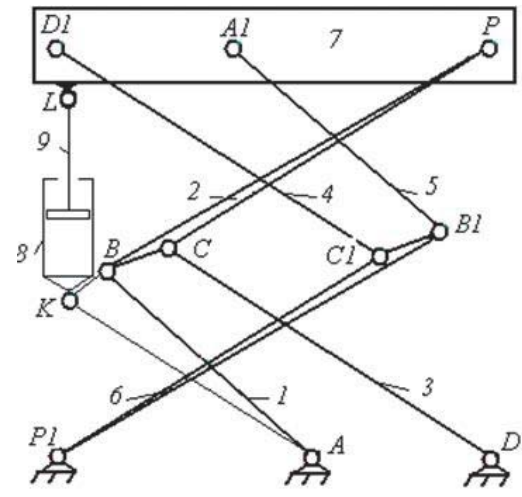

Figure 1 - The kinematical scheme of eight-linked load lifting joint linkage

In Figure 1 mechanism $A B C D$ - four-linked planar joint linkage. In this mechanism point $\mathrm{P}$ which fits $\mathrm{BC}$ is moving straight in vertical direction. The altitude is varying from 0,4 till 2,5 meters. Now we joint to current mechanism symmetrically inverted $A_{1} B_{1} C_{1} D_{1} P_{1}$ mechanism with load lifting platform-7 through point $P$ and get 8-linked mechanism. The platform-7 of this mechanism would describe linear motion. We will consider this mechanism by two measures.

The lengths of mechanism are given: $I_{A B}=I_{A 1 B 1}=0,96 ; I_{C D}=I_{C 1 D 1}=1,61 ; \quad I_{B 1 P 1}=I_{B P}=2,08 ; \quad I_{B C}=I_{B 1 C 1}=0,49 ; \quad I_{A K}=0,91$; $I_{B K}=0,21 ; I_{A 1 P}=0,89$. Absolute coordinates of leg joints $X A=0.337, X P 1=-0.55 \mathrm{M}, X D=1.5 \mathrm{M}, Y A=0, Y P 1=0, Y D=0$ are constant.

The main difference between our mechanism and traditional planar linkages is that the hydro cylindrical chain connects two movable links. Input kinematical chain KLM is hydro cylindrical chain consisting of 8- and 9-links. In "conditional Assur group": number of links is 8 and number of joints is $P_{5}=12$. That's why degree of freedom in "conditional Assur group" is $W=3 \cdot 8-2 \cdot 12=0$. So, examined "conditional Assur group" is kinetostatically defined. We can write 3 equality equations for each 8 links (forces and moment equality), number of unknown reactions is 24 (each 12 joints have 2 unknown reactions).

Consider as external forces only $\vec{F}_{i}$ - weight force acting on each link at $S_{i}$ - center of mass, $i=1, \ldots, 8$. For kinetostatics analysis assume that location of all links are to be known. It means we assume that absolute coordinates of all joints as well as absolute coordinates of all mass centers ${ }^{X s_{i}}, Y s_{i}$ are known.

In given external forces the force acting on link 7 because it is load lifting platform is consists of gravity force and gravity force of useful load.

In order to form equality equation lets consider the forces effecting on ABK triangle in mechanism's scheme. The equilibrium force $\vec{F} i\left(\begin{array}{l}x \\ y\end{array}\right)=0$ on link 1 will be:

$$
F_{1}^{x}+R_{01}^{x}+R_{21}^{x}+R_{81}^{x}=0, \quad F_{1}^{x}+R_{01}^{x}+R_{21}^{x}+R_{81}^{x}=0
$$

and equation of moment $\sum_{\text {in }} M_{A}=0$ relative to point $\mathrm{A}$ is:

$$
\begin{aligned}
& F_{1}^{y}\left(X_{S 1}-X_{A}\right)+F_{1}^{x}\left(Y_{A}-Y_{S 1}\right)+R_{81}^{y}\left(X_{K}-X_{A}\right)+ \\
& +\left(Y_{A}-Y_{R}\right) R_{81}^{x}+R_{21}^{y}\left(X_{B}-X_{A}\right)+R_{21}^{x}\left(Y_{A}-Y_{B}\right)=0
\end{aligned}
$$

Thus, we make 24 equations with 24 unknown reactions.

Mass of links are proportional to its length and values are : $\mathrm{m} 1=40 \mathrm{~kg}, \mathrm{~m} 2=40 \mathrm{~kg} ; \mathrm{m} 3=130 \mathrm{~kg}, \mathrm{~m} 4=130 \mathrm{~kg}, \mathrm{~m} 5=$ $70 \mathrm{~kg} ; \mathrm{m} 6=130 \mathrm{~kg} ; \mathrm{m} 7=500 \mathrm{~kg}$; ( i.e. platform's mass $500 \mathrm{~kg}$ ); $\mathrm{m} 8=50 \mathrm{~kg}$; since it is a pair of mechanism platform carries $1000 \mathrm{~kg}$ weight. 
Representing unknown reactions as vectors $\overrightarrow{\mathrm{R}}=\left[\begin{array}{llll}\mathrm{R}_{1}, \mathrm{R}_{2}, \ldots & \mathrm{R}_{24}\end{array}\right]$. To determine reactions write equilibrium equation in matrix form : $A \cdot \vec{R}=\vec{F}$, where A - main matrix 24x24 and $\vec{R}$ - unknown, $\vec{F}$ - right side forces.

Equation based $A$ - main matrix:

$A(1,1)=1: A(1,3)=1: A(1,5)=1 A(2,2)=1: A(2,4)=1: A(2,6)=1$

$A(3,3)=Y A-Y B: A(3,4)=X B-X A: A(3,5)=Y A-Y K: A(3,6)=X K-X A$

$A(4,3)=-1: A(4,7)=1: A(4,9)=1 A(5,4)=-1: A(5,8)=1: A(5,10)=1$

$A(6,3)=Y B-Y C: A(6,4)=X C-X B: A(6,9)=Y C-Y P: A(6,10)=X P-X C$

$A(7,7)=-1: A(7,11)=1 A(8,8)=-1: A(8,12)=1$

$A(9,7)=Y C-Y D: A(9,8)=X D-X C$

$A(10,13)=1: A(10,15)=1 A(11,14)=1: A(11,16)=1$

$A(12,13)=Y D 1-Y C 1: A(12,14)=X C 1-X D 1$

$A(13,17)=1: A(13,19)=1 A(14,18)=1: A(14,20)=1$

$A(15,19)=Y B 1-Y A 1: A(15,20)=X A 1-X B 1$

$A(16,13)=-1: A(16,17)=-1: A(16,21)=1$

$A(17,14)=-1: A(17,18)=-1: A(17,22)=1$

$A(18,13)=Y C 1-Y P 1: A(18,14)=X P 1-X C 1$

$A(18,17)=Y B 1-Y P 1 ; A(18,18)=X P 1-X B 1$

$A(19,9)=-1: A(19,15)=-1: A(19,19)=-1: A(19,23)=1$

$A(20,10)=-1: A(20,16)=-1: A(20,20)=-1: A(20,24)=1$

$A(21,9)=Y P-Y D 1: A(21,10)=X D 1-X P: A(21,19)=Y A 1-Y D 1$

$A(21,20)=X D 1-X A 1: A(21,23)=Y D 1-Y L: A(21,24)=X L-X D 1$

$A(22,5)=-1: A(22,23)=-1 A(23,6)=-1: A(23,24)=-1$

$A(24,23)=Y L-Y K: A(24,24)=X K-X L$

$\vec{F}$ - right side forces' matrix:

$F(1)=-F X 1: F(2)=-F Y 1: F(3)=-F X 1$ * $(Y A-Y S 1)-F Y 1$ * $(X S 1-X A)$

$F(4)=-F X 2: F(5)=-F Y 2: F(6)=-F X 2$ * $(Y C-Y S 2)-F Y 2$ * $(X S 2-X C)$

$F(7)=-F X 3: F(8)=-F Y 3: F(9)=-F X 3 *(Y D-Y S 3)-F Y 3 *(X S 3-X D)$

$F(10)=-F X 4: F(11)=-F Y 4: F(12)=-F X 4 *(Y D 1-Y S 4)-F Y 4 *(X S 4-X D 1)$

$F(13)=-F X 5: F(14)=-F Y 5: F(15)=-F X 5 *(Y B 1-Y S)-F Y 5 *(X S 5-X B 1)$

$F(16)=-F X 6: F(17)=-F Y 6: F(18)=-F X 6$ * $(Y P 1-Y S 6)-F Y 6$ * $(X S 6-X P 1)$

$F(19)=-F X 7: F(20)=-F Y 7: F(21)=-F X 7$ * $(Y D 1-Y S 7)-F Y 7 *(X S 7-X D 1)$

$F(22)=-F X 8: F(23)=-F Y 8: F(24)=-F X 8$ * $(Y K-Y S 8)-F Y 8 *(X S 8-X K)$

To solve equilibrium system we wrote a Visual Basic program using Gauss method in Microsoft Office Excel software. Program determines mechanism's reactions, ten values are placed in table.

Optimal design of hydrocylindrical chain. Now lets consider main goal of the problem. In mechanism scheme hydrocylinder connects $A B$ link and platform. Taking in consideration hydrocylindrical chain calculate mechanism's force transmission effectively. For that reason determine hydrocylindrical connection points where value of ${ }^{\text {Fener }}=R_{81}$ force is minimum. Also we determine the values of $(K L)_{\min },(K L)_{\max }$.

Formula to determine length of hydrocylindrical chain :

$K L=\sqrt{\left(X_{K}-X_{L}\right)^{2}+\left(Y_{K}-Y_{L}\right)^{2}}$

Now, evaluate absolute coordinates of $\mathrm{K}$ and $\mathrm{L}$ kinematic pair:

$X K=X A+x_{K}{ }_{-} l o c \cos \beta_{1}-y_{K}-l o c \sin \beta$

$Y K=Y A+x_{K}$ loc $\sin \beta+y_{K}$ loc $\cos \beta$

$X L=X D 1+x_{L_{-}} l o c \cos \beta_{1}-y_{L_{-}} l o c \sin \beta$

$Y L=Y D 1+x_{L}{ }_{-} l o c \sin \beta+y_{L-} l o c \cos \beta$

Varying parameters $x_{K} l o c, y_{K} l_{l} l o c$ and $x_{L_{-}} l o c, y_{L_{-}} l o c$ are local coordinates of $\mathrm{K}$ and $\mathrm{L}$ joints. To find the minimum of force in hydrocylinder we use three criteria. First criteria $C 1$ is equal to maximum values of all reactions, second one $\mathrm{C} 2$ is equal to maximum value of equilibrium force in hydrocylinder and the last one $\mathrm{C} 3$ additional condition solving constructional limits. 
$\mathrm{C} 1=\mathrm{Rmax} \mathrm{C2}=\mathrm{F}_{\mathrm{yp}} \mathrm{C} 3=\mathrm{KLmax} / \mathrm{KImin}$

The constructor choosing the right and the left limits for these criteria.

1 -stage. In order to check the capabilities of mechanism we choose the limits in this way:

$0<C 1<800000<C 2<450000<C 3<1000$

We can change the values of variation variables $\pi \Pi_{\tau}$-sequence by using the generator:

$x_{K}$ loc $=0.3 \div 1.2 ; \quad y_{K}{ }_{-} l o c=-0,1 \div 0,2$;

$x_{L}$ loc $=-0,1 \div 2,1 ; \quad y_{L_{-}} l o c=-0,1 \div 0,16$.

We put Lptau [12] subroutine in Sub pos() program and calculate.

We can get 644 mechanisms if we verify $32000 \pi \Pi_{\tau}$ point. The table is written below in ascending order. 4 mechanisms were chosen. The parameters are in table 1. At the end only one mechanism was chosen (table 2).

Table 1 - Table of selected mechanism

\begin{tabular}{|c|c|c|c|c|c|c|c|c|c|}
\hline Alpt & xK-Loc & yK-Loc & xL-Loc & yL-Loc & \$1 & \$2 & \$3 & KLmin & Klmax \\
\hline 8437 & 0.915 & 0.197 & 0.912 & 0.007 & 29145 & 21131 & 1.74 & 1.01 & 1.75 \\
\hline 5797 & 0.882 & 0.195 & 1.080 & -0.034 & 29755 & 27476 & 1.58 & 1.13 & 1.78 \\
\hline 12601 & 0.850 & 0.182 & 1.042 & -0.023 & 28400 & 24688 & 1.70 & 1.06 & 1.80 \\
\hline
\end{tabular}

Table 2 - Table of selected mechanism

\begin{tabular}{|c|c|c|c|c|c|c|c|c|c|}
\hline Alpt & $x K-L o c$ & $y K-L o c$ & $x L-L o c$ & $y L-L o c$ & $\boldsymbol{~} 1$ & $\boldsymbol{\phi 2}$ & $\boldsymbol{\phi 3}$ & KLmin & KImax \\
\hline 8437 & 0.915 & 0.197 & 0.912 & 0.007 & 29145 & 21131 & 1.74 & 1.01 & 1.75 \\
\hline
\end{tabular}

\section{Conclusion}

Scientific novelty of the proposed model load lifting device has an increased stiffness compared with the prototype, because platform and base are connected to the actuator by means of three joints. Constructional complex progressive kinematical pairs of rollers are eliminated.

- Increased stiffness compared with the prototype, because platform and base are connected to the actuator by means of three joints.

- Efficient power transmission in drive: in a lower position: less than 3 times compared to analogs.

- Constructively simple: the translational complex kinematical pairs are eliminated (without rollers, friction, etc.).

- Stability is high: loading platform is more stable in the top positions.

Prospects for further research in this area. The creation of scientific engineering and design offices for the organization of domestic developments in the design of the lifting devices. Creation of scientific and technological basis for achieving the objective of the engineering industry of the Republic of Kazakhstan. The development of new technologies import products.

\section{References}

Dzholdasbekov U. THEORY MECHANISMS OF HIGH GRADES.. - Almaty: Gylym, 2001. - 428 p.

Ibrayev S.M. Functional synthesis and analysis of planar parallel manipulators.- Almaty: Gylym, 1996. - 198 p.

Ualiev G.U.Dynamics of machines and mechanisms. - Almaty: «AGU - Tauar». 2000. - 282 p.

Ibrayev S.M. / Research Report on the program of fundamental study researches RK state registration number F0369 0106 RK0067 2007year.

RU 51006 U1. Ascheulov A.V., Kharitonov N.A., Solodkov D.A. LIFT. 01/27/2006 Bull. Number 03.

RU 62390 Mahozhev M.M., LIFT.10.04.2007 Bull. Number 10

RU 2280007 C1 Eliseev, A.K., Saldaev A.M., Saldaev N.D., LIFT.20.07.2006 Bull. № 20

RU 2268239 C2 Saldaev A.M., Rogachev A.F. LIFT 20.01.2006 Bull. № 02. 20.01.2006

LIFT /Trudler M.V.and Pak D.A. (USSR). - Application № 3649886/27-11; 05.10.1983, publ. 23.05.1986, Bull. № 19 / / Discoveries. Invention. - 1986. - № 19.

RU 2308 412C1 Saldaev A. M., Saldaev N.D., Saldaeva U.G., Saldaev D. A. LIFT 20.10.2007 Bull; . № 29

RU 2297974 Koval E.P. Hing-lever mechanism. 27.04.2007

Sable I.M., Statnikov R.B., selection of optimal parameters in problems with many criteria-M.: Drofa, 2006. -175 p. 
Angeles, J. The robust design of parallel manipulators.- Proc. of 1st Int. Colloquium of the SFB 562, Branschweig, Germany, 9-30, 2002. Brior S., Arakeliun V., Singularity Analysis of PAMINSA Manipulators.- In the same Conference proceedings, 2007.-vol.5, pp. 453-458.

Chablat D., Wenger Ph. Architecture Optimization of a 3-DOF Parallel Mechanism for Machining Applications, the Orthoglide.- IEEE Trans. Robotics and Automation, June, 2003.

Chablat D., Wenger Ph., Merlet J.-P. A Comparative Study between Two Three-DOF Parallel Kinematic Machines using Kinetostatic Criteria and Interval Analysis- Proc. of 11th World Congress in MMS.- April 1-4, 2004, Tianjin, China. - Vol.3, 2004, pp.12091213.

Chen T.I.-M., Li C., Angeles J. Managing Singularities of 3-DOF Planar Parallel Manipulators Using Joint-Coupling.- In the same Conference proceedings, 2004, Tianjin, China, 2004, pp. 1966-1970.

Elkribi B., Affi Z., Romdhane L. Multi-objective Genetic algorithm Optimization of a mechatronic System. Proceedings of the $12^{\text {th }}$ IFToMM World Congress in Mech.\&Mach.Sci., Besancon, France, June 18-21, 2007.-vol.2.

Gogu G., Structural synthesis of fully-isotropic translational parallel robots via theory of linear transformations. European Journal of Mechanics, 23(6), 1021-1039, 2004.

Gosselin, C., Angeles, J., The Optimum Kinematic Design on a Spherical Three-d.o.f. Parallel Manipulator, ASME Journal of Mech., Transm. and Automation in Design, 111 (1989), s.202-207.

Hesselbach J., Kerle H., Kreft M., Plitea N. The Assessment of Parallel Mechanical Structures for Machines Taking Account of Their Operational Purposes.- Proc. of 11th World Congress in MMS.- April 1-4, 2004, Tianjin, China, Vol.3, 2004,- pp.1234-1239. 